\title{
Using Learning Theories to Develop a Veterinary Student Preparedness Toolkit for Workplace Clinical Training
}

Jennifer Routh ${ }^{1 *}$, Sharmini Julita Paramasivam ${ }^{1}$, Peter Cockcroft ${ }^{1}$, Vishna Devi Nadarajah ${ }^{2}$, Kamalan Jeevaratnam ${ }^{1^{*}}$

${ }^{1}$ School of Veterinary Medicine, University of Surrey, Guildford, UK

${ }^{2}$ Division of Human Biology, School of Medicine and IMU Centre for Education, International Medical University, Kuala Lumpur, Malaysia

*Correspondence:

Corresponding Authors:

j.routh@surrey.ac.uk,drkamalanjeeva@gmail.com

Keywords: learning theory, preparedness, preceptorship, veterinary education, workplace learning, clinical rotations 


\section{Table of Contents}

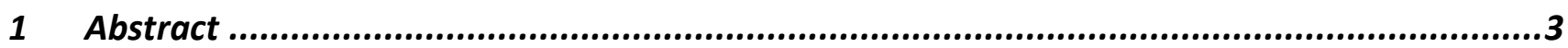

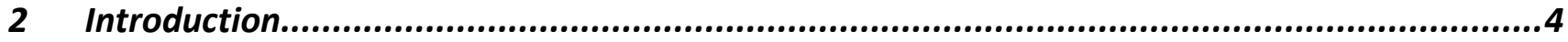

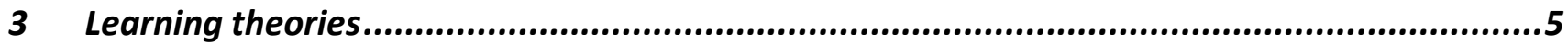

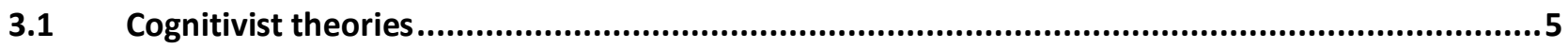

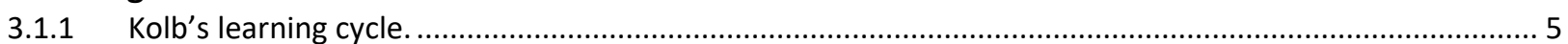

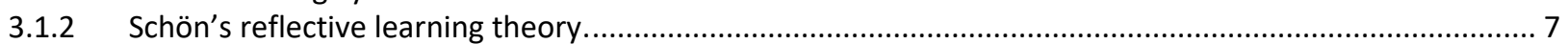

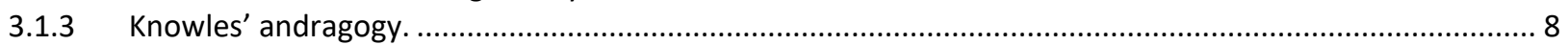

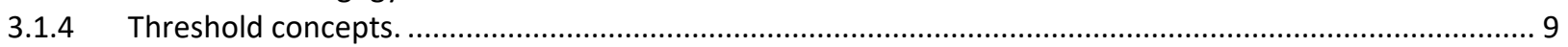

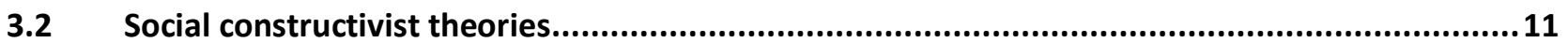

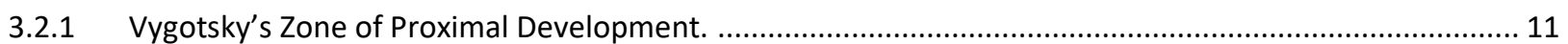

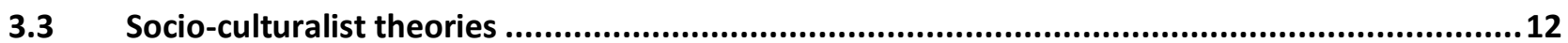

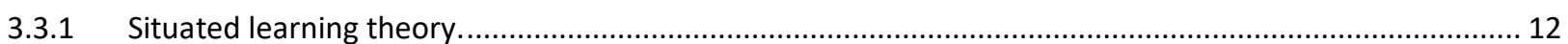

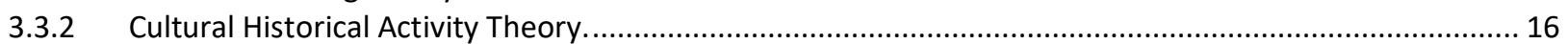

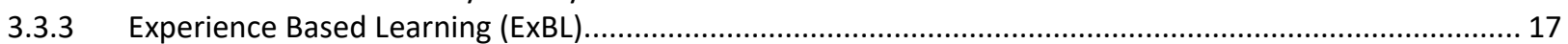

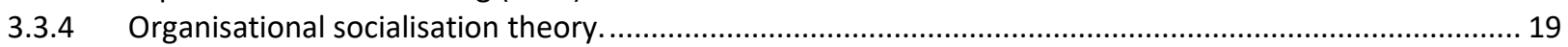

3.3.5 Billet's theory of workplace affordances and individual engagements............................................... 20

4 Discussion: inferences about student preparedness ...............................................21

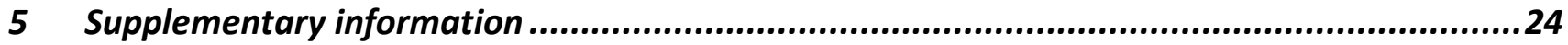

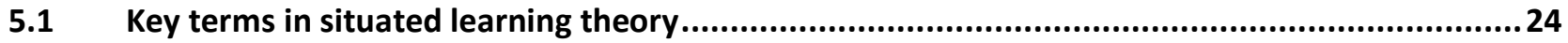

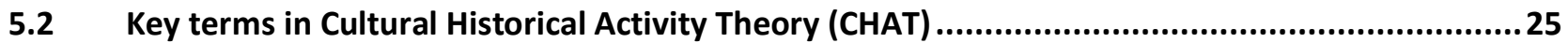

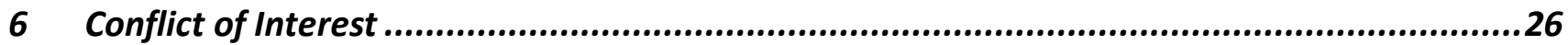

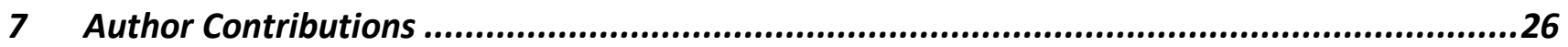

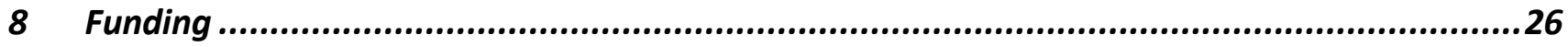

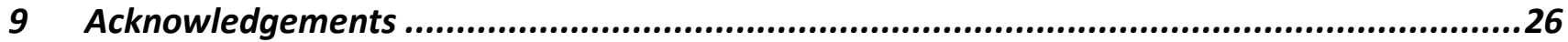

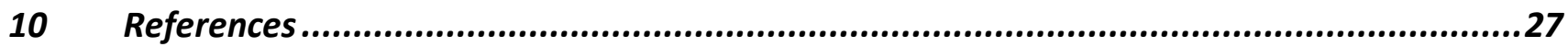




\section{Abstract}

Learning theories are logically related statements designed to explain what should or could be aspired to in establishing ideal learning conditions. Multiple theories can inform our understanding of a single concept, in this case: veterinary workplace clinical training (WCT), which occurs just prior to students' graduation as competent veterinary surgeons. The competency movement has strongly influenced reforms in veterinary education and is considered important. In reflection of this, the term "preparedness" is operationalised here as a measure of the likelihood that the veterinary student is going to be a competent learner and participant during WCT. Preparedness itself is therefore important because it directly impacts performance. Workplace clinical training is explored through the lenses of cognitivist, social constructivist and socio-culturalist learning theories and used to inform student preparedness characteristics in terms of their behaviours, personal attributes, knowledge and skills, and awarenesses to optimise learning and participation. 


\section{Introduction}

Veterinary workplace clinical training (WCT) comprises an essential part of the veterinary curriculum and typically takes place in the final 12-24 months of the programme. A form of preceptorship (1), students learn through authentic but supervised participation in 'real-world' veterinary practice. Workplace clinical training consists of experiential, informal and opportunistic teaching approaches, albeit guided by structured objective setting and assessment frameworks. It can be located in a number of different types of facilities including university-owned teaching hospitals and clinics, or private practice as part of a distributed curriculum. Often several different types of facility are used for WCT within a programme. Through the integration and application of knowledge, alongside the development of key skills, attributes and professional identity, students transition to competent veterinarians. The development of competency during WCT is critical given that veterinary graduates are licensed to practice unsupervised when they leave the programme, albeit with structured support. Veterinary institutions must therefore ensure that graduates gain the competences required to meet the standards of their statutory registration body to ensure they are able to practice safely and professionally.

Workplace-based medical education has been identified as a 'black box' (2); the output is clear but the inner workings are difficult to understand. In a similar way and having developed haphazardly from apprenticeship principles, our direct understanding of how veterinary students learn during WCT is imperfect. In addition, there is limited use and application of learning theories in clinical veterinary education (3-8) which is not representative of their potential usefulness in understanding education practices (9). Indeed, Schoenfeld-Tacher and Baker (10) assess that it's no longer appropriate to expect a clinician to be an outstanding teacher without the appreciation of the underlying principles of learning. As such, theory and practice are linked in a bidirectional manner; theory has the potential to inform practice and to be informed by it (11).

Using learning theory to open the lid of the 'black box' and understand the underlying pedagogy of WCT could help us to prepare students for their experiences. Improving preparedness, defined here as "are you going to be a competent learner and participant of WCT?" (12), should improve student competency and produce veterinarians better able to serve the needs of society. The aim of this work is to review selected learning theories, explore how they can be applied to veterinary WCT, and to inform student preparation for it. 


\section{Learning theories}

According to Bordage (13), different conceptual frameworks can be used to illuminate or magnify different aspects of a complex system, such as an education programme. Additionally, no one theory can adequately explain or justify the entire system. It is therefore both 'necessary and confusing' to acknowledge that there will be many appropriate conceptual frameworks applicable to the topic of interest (14). The ways in which a range of theories align with WCT will be discussed in this paper. These theories are discussed in turn within their overarching schools of thought: cognitivism, social constructivism, and socio-culturalism.

\subsection{Cognitivist theories}

Cognitivism focuses on individual psychology and in the context of workplace learning is concerned with the epistemology of professional practice, in other words how do we know how to be a veterinary surgeon? As such, its explanatory power is limited to the individual student. Cognitivism endeavours to explain how knowledge and skills are acquired through transmission (with the input of another resource) and constructivism. Constructivism is important to consider in the context of WCT. It describes how knowledge, meaning or learning is 'constructed' and integrated into an expanding but existing network with experience. Nothing is learned from scratch; knowledge is assimilated or reinterpreted in the light of the learner's existing understanding and ability (15). The influence of constructivist concepts such as andragogy (16) and reflective learning (17) is exemplified by the adoption of portfolios, personal development logs and learning objective planning in veterinary curricula.

\subsubsection{Kolb's learning cycle.}

Kolb's learning cycle combines the models of learning developed by Dewey, Lewin and Piaget (15). The cycle describes how knowledge is continuously derived from and tested out in the experiences of the learner, and Kolb is credited with proposing that reflection is how learners abstract and transfer their learning to new contexts. In the constructivist style, Kolb states that all learning is re-learning; learners' minds are not blank sheets of paper. This aligns readily with veterinary students entering WCT, their sheet of paper already populated with some concepts already (for example their knowledge of anatomy, pathology, microbiology). It is by their experiences in the workplace that students learn how to integrate and apply these subjects in the practice of veterinary medicine.

The learning that Kolb describes is more extensive than that which occurs in the confines of the lecture theatre; learning occurs in all settings (including the workplace) and is lifelong. Additionally, it encompasses not only knowledge acquisition, but the cycle can be applied to other cognitive concepts such as decision making and problem-solving. Learning is viewed by Kolb as a holistic process and involves thinking, feeling, perceiving, and behaving. All these facets of the theory make it attractive for application to veterinary WCT (Table 1). 
Table 1: The stages of Kolb's learning cycle, applied to veterinary workplace clinical training (WCT) and inferred student preparedness characteristics

\begin{tabular}{|c|c|c|}
\hline $\begin{array}{l}\text { Stage of Kolb's } \\
\text { learning cycle }\end{array}$ & $\begin{array}{l}\text { Applied to veterinary student } \\
\text { workplace clinical training (WCT) }\end{array}$ & Inferred student preparedness characteristics \\
\hline Concrete experience & $\begin{array}{l}\text { Students must gain experience in many } \\
\text { clinical areas as part of their WCT. } \\
\text { The more granular experiences } \\
\text { expected may be prescribed in a list for } \\
\text { students prior to commencing, e.g. the } \\
\text { student is assigned to a real patient, } \\
\text { takes clinical history and performs } \\
\text { clinical exam. }\end{array}$ & $\begin{array}{l}\text { Students should be prepared to immerse } \\
\text { themselves fully in the activity of the workplace } \\
\text { to have concrete (i.e., authentic) experiences. } \\
\text { Individuals need to harness the opportunities } \\
\text { that arise in the workplace, which may be on an } \\
\text { ad hoc basis. As such students will require an } \\
\text { awareness of what their potential experiences } \\
\text { are and what they can get out of them - without } \\
\text { preparation students may overlook } \\
\text { opportunities to learn. }\end{array}$ \\
\hline $\begin{array}{l}\text { Reflective } \\
\text { observation } \\
\text { (reflecting on the } \\
\text { experience) }\end{array}$ & $\begin{array}{l}\text { The student 'makes sense' of what they } \\
\text { experienced; they reflect on the } \\
\text { encounter. This may be triggered by a } \\
\text { clinical supervisor in feedback dialogue } \\
\text { or in the writing of a reflective report. }\end{array}$ & $\begin{array}{l}\text { Students should be proficient at reflection and } \\
\text { recognising their experiences from other } \\
\text { perspectives. They should be proactive and seek } \\
\text { formative feedback in order to facilitate their } \\
\text { reflection (18); it should not be assumed that } \\
\text { feedback is part of every practice culture. }\end{array}$ \\
\hline $\begin{array}{l}\text { Abstract } \\
\text { conceptualisation } \\
\text { (generating new } \\
\text { approaches) }\end{array}$ & $\begin{array}{l}\text { The student uses the reflective process } \\
\text { to generate new approaches to self- } \\
\text { improvement; what they need to learn } \\
\text { to build on existing knowledge or } \\
\text { improve techniques. This could be } \\
\text { evidenced in a written portfolio or } \\
\text { through the setting of personalised } \\
\text { learning objectives. }\end{array}$ & $\begin{array}{l}\text { To be well prepared for WCT students should be } \\
\text { capable in self-directed learning. }\end{array}$ \\
\hline $\begin{array}{l}\text { Active experiment } \\
\text { (testing new } \\
\text { approaches) }\end{array}$ & $\begin{array}{l}\text { The student tests their new approach in } \\
\text { their next experience for example, new } \\
\text { interviewing skills, physical exam } \\
\text { techniques or approaches to clinical } \\
\text { reasoning. The result is that students } \\
\text { gain the skills or knowledge required } \\
\text { within the clinical area. }\end{array}$ & $\begin{array}{l}\text { Students need to plan new actions to promote } \\
\text { further experiential learning, this could include } \\
\text { discussions with workplace supervisors to } \\
\text { arrange upcoming opportunities. }\end{array}$ \\
\hline
\end{tabular}


Greenberg and Blatt (19) provide a guide for medical students in negotiating their undergraduate WCT equivalent, based on Kolb's learning cycle. They propose a preparatory fifth stage suggesting that students should learn and be prepared to implement adult learning principles and Kolb's experiential learning cycle. They state that students should identify their roles and responsibilities prior to commencing training to give them confidence in seeking out concrete experiences. Students also need to understand that they must act within their boundaries and to be certain that clients understand their level of training; experiences must be appropriate for the training level.

\subsubsection{Schön's reflective learning theory.}

Schön's reflective learning theory (17) specifically addresses learning in contexts of uncertainty, working in the 'swamp' with messy and confusing problems. The veterinary workplace is swamp-like, it can be unpredictable and difficult to see a clear path to take to solve patients' problems. Clinical cases presented are often not as the textbook would describe but are unique and might require improvisation. Schön theorises that practitioners work in the 'indeterminate zones of practice', characterised by this uncertainty, uniqueness, where values might conflict, and 'technical rationality' can fall down. Schön developed the concept of the 'reflective practitioner' to help students acquire the kind of artistry essential to professional competence in these indeterminate zones of practice.

Firstly, we consider 'reflecting in action', where, without interrupting action, thinking reshapes the action. 'Reflecting in action' can be likened to trial and error, but successive trials have an immediate significance for the next action; they are iterative, and trials are not performed at random. A good example would be a veterinary student making attempts at venepuncture, redirecting the needle each time based upon their quick reflections in the action. Students will also need to be prepared for performing the on-the-spot experiments of 'reflecting in action' in the workplace by putting their knowledge to the test in other contexts. An example would be the recognition of clinical signs or proposing treatment options for a disease known in one species to another.

Secondly, we consider 'reflecting on action', the 'stop and think' phase, where practitioners reflect later, after an event. Schön explains that it is crucial that a learner thinks about the processes that they have used and the extent to which they were appropriate. In the veterinary workplace reflecting on action can be facilitated using reflective journals or portfolios in addition to feedback from supervisors.

Schön theorises that reflective practice (both in and on action) becomes a vehicle for learning effectively in the professional environment and may be integrated into future 'knowing in action' or 'professional artistry' (11). Students will need to graduate omnicompetent not omniscient, it is not possible to know everything (20), and reflection is key to managing this insurmountable challenge. In other words, without reflection contextual learning will be trapped in the precise context in which it was learnt. Reflection is evidently something that students must be prepared for. 


\subsubsection{Knowles' andragogy.}

With roots in humanistic psychology, the foundation of Knowles' somewhat controversial andragogy was initially to distinguish between the ways in which children and adults learn (pedagogy versus andragogy) (16). Andragogy is presented as a series of assumptions about the adult learner (Table 2), as opposed to being a learning theory itself $(4,21,22)$. Andragogy is stated in terms of the learners' behaviour as opposed to teachers' actions, and therefore could be utilised to infer how students might be prepared for WCT.

Table 2: The assumptions of andragogy applied to veterinary workplace clinical training (WCT)

\begin{tabular}{|l|l|}
\hline $\begin{array}{l}\text { Andragogy describes the adult } \\
\text { learner as... }\end{array}$ & Applied to veterinary WCT \\
\hline Independent and self-directed & $\begin{array}{l}\text { Andragogy is fostered by a curriculum strongly focused on self- } \\
\text { directed learning which, in the absence of formal didactic } \\
\text { teaching, instinctively aligns well with veterinary WCT. }\end{array}$ \\
\hline $\begin{array}{l}\text { Having accumulated a reservoir of life } \\
\text { experiences that are a rich source for } \\
\text { learning }\end{array}$ & $\begin{array}{l}\text { Both through their life pre-training and their university career } \\
\text { (for example through participation in extra-mural studies in the } \\
\text { UK), students will have gained their own knowledge, experiences } \\
\text { and expectations, which they bring to the workplace. }\end{array}$ \\
\hline $\begin{array}{l}\text { Having learning needs closely related } \\
\text { to changing social roles }\end{array}$ & $\begin{array}{l}\text { In the clinic or hospital students can clearly relate their patient- } \\
\text { centered work and learning to their changing societal role as a } \\
\text { veterinary professional. }\end{array}$ \\
\hline $\begin{array}{l}\text { Problem centered and interested in } \\
\text { immediate application of knowledge } \\
\text { than external factors }\end{array}$ & $\begin{array}{l}\text { In the final year as graduation draws closer, students are } \\
\text { internally motivated by the need to become competent } \\
\text { practicing veterinarians, which can be promoted by self-selected } \\
\text { placements (electives). This is provided that curriculum overload } \\
\text { or overwhelming assessments do not force students to revert } \\
\text { back to rote memorisation of facts in order to keep up or pass. }\end{array}$ \\
\hline
\end{tabular}

In work by Matthew et al $(23,24)$ a cohesive conception of WCT learning by veterinary students (learning the contextual variation that affects the management of cases in real-world veterinary practice) was associated with deep learning approaches. These approaches were strongly andragogical; they emphasised independent, reflective and self-directed learning alongside intrinsic motivation and satisfaction in progressing towards competency in practice. Veterinary students adopting such an approach performed better in assessments of WCT, which were an indicator of 
practice readiness. This provides evidence of the importance of these andragogical approaches, which students should be prepared with.

In an 'adult' classroom, learners should feel accepted, respected and supported with a spirit of joint enquiry between teachers and students (16). Therefore, in addition to internal motivation and selfdirected learning skills, students should be prepared for the dynamics of the relationship with their educators to change with the transition to WCT. Instead of being presented with information by lecturers, students should feel prepared to be part of the clinical team, solving problems alongside their teacher clinicians.

\subsubsection{Threshold concepts.}

When considering student preparedness for WCT, Meyer and Land's threshold concepts offer promise as a useful tool $(25,26)$. Likened to a portal, threshold concepts are ideas that are necessary for a student to possess in order to progress in their learning, and eventually enable them to think like a professional. They are transformational and change the way that the student thinks about a concept, not just what they know about it. Threshold concepts could be thought of as keys to preparedness for the next stage of learning, or which allow students to participate effectively in the workplace.

Attempts have been made to examine threshold concepts in veterinary education (27). Pharmacology and neurology areas were identified as the most challenging subjects across the entire curriculum in two separate schools, which is part-way towards classification as a threshold concept. However, the study was unable to determine any areas that once understood transformed students' way of thinking or professional development, and therefore could not identify any legitimate threshold concepts.

Threshold concepts have been assessed in human medicine (28-30). Bhat et al (28) describe nine threshold concepts that junior trainees may encounter during an internal medicine rotation (Figure 1). Additionally, working with uncertainty, considering the bigger picture, not needing to know everything and professional culture have been identified as threshold concepts for professionalism learning in undergraduate medicine (30). These could be considered as candidate preparedness characteristics for veterinary WCT.

Gaunt and Loffman (31) explain that medical students should be prepared to seek out opportunities to tackle threshold concepts. If students understand that by accomplishing threshold concepts, they will unlock new ways of thinking previously closed off to them, it will create more confident and curious learners with a professional mindset that can succeed in the workplace. 


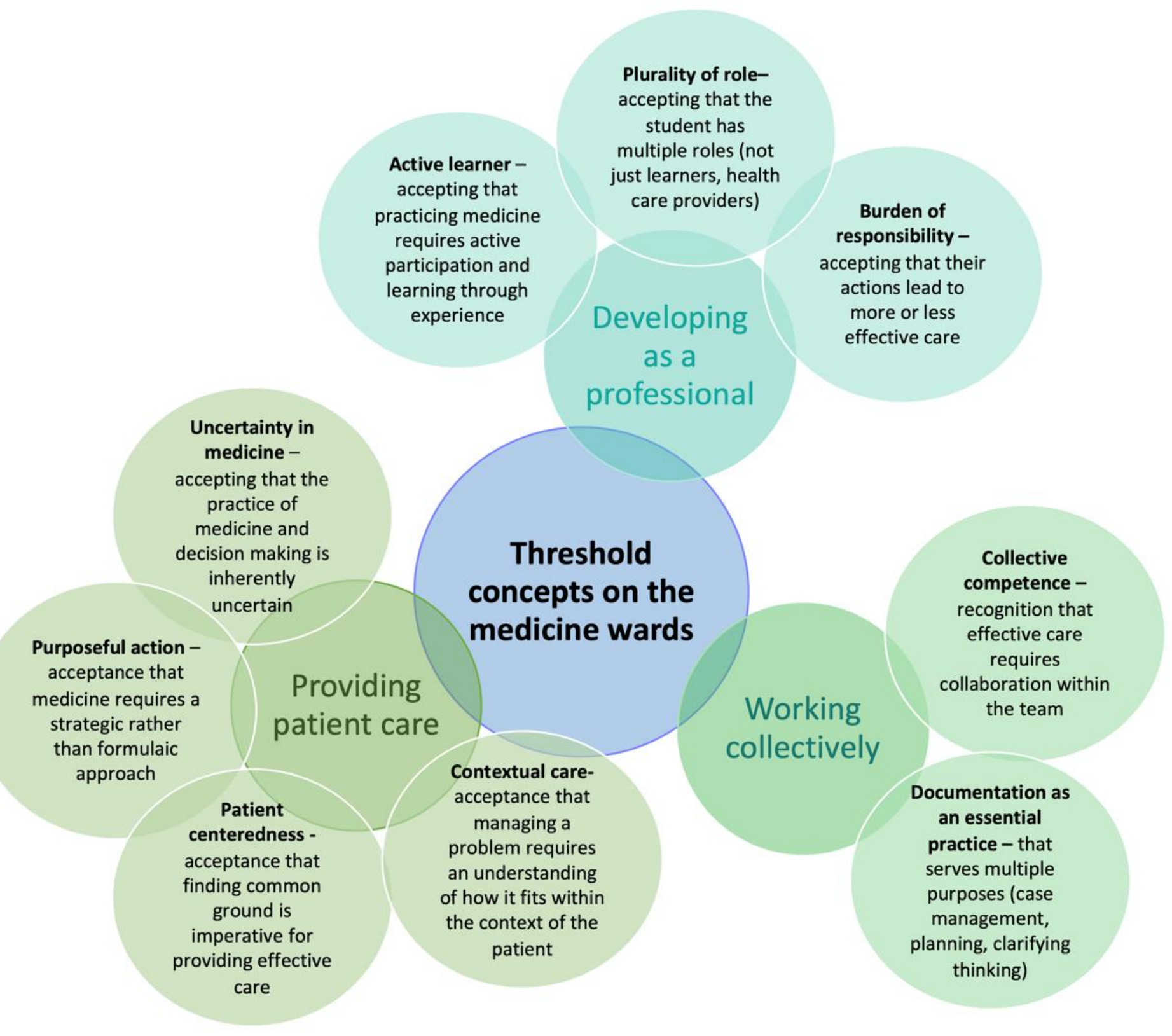

Figure 1: Threshold concepts encountered by junior trainees on an internal medicine rotation, content from Bhat et al, (2018) (28). 


\subsection{Social constructivist theories}

Like cognitivism, in social constructivism focus remains on the individual's internal mind. However social constructivism contrasts with the independent learning embedded in much of the cognitivist theories and formal, classroom based, veterinary education; these theories explore how learning can be shaped by the engagement of experience with others.

\subsubsection{Vygotsky's Zone of Proximal Development.}

Through his work to describe the zone of proximal development (ZoPD), Vygotsky is a key contributor to social constructivism (32). He depicts the ZoPD as the gap between 1) a students' actual developmental level, which is their proven, independent mental function and 2) the level of potential development which can be established by problem-solving under the guidance of, or in collaboration with, more capable others (32).

There are three key features of the ZoPD theory that can be taken forward into WCT (33). Firstly, the use of 'tools' to 'mediate' learning. Using patients as a scaffold for learning is the central tenet of WCT and they are fundamentally a teaching tool. Using diagnostic images, laboratory results or case notes would be other physical examples, but tools can also be symbolic such as mnemonics to help remember differential diagnoses. Secondly, identifying learners' actual developmental level and their learning potential. Students could prepare for their placements by considering and even communicating their actual developmental level, and identify gaps in their knowledge or skills, which is expected by veterinary clinical supervisors (34). Thirdly, students should prepare to learn from the entire clinical team. If one locates learning in the social arena of a workplace, a whole community (veterinary surgeons, nurses, receptionists) opens up to assisting with navigation across the ZoPD. The value of near-peer education also aligns well with the social nature of Vygotsky's theory, particularly when considering preparing for transitions to new working environments. The 'student grapevine' (acquiring information from students who have previously experienced that WCT environment) has been identified in both the medical $(35,36)$ and veterinary $(34,37)$ settings. 


\subsection{Socio-culturalist theories}

Learning in complex and dynamic systems such as the veterinary workplace cannot be wholly explained by cognitive or constructivist theories alone and is perhaps best understood from a sociocultural viewpoint. Socio-cultural learning theories underlie the learning-as-participation metaphor (as opposed to learning-as-acquisition) (38). The goal is the full, authentic participation in the work of a community, which has a striking resemblance to the aims of veterinary WCT.

\subsubsection{Situated learning theory.}

Lave and Wenger (39) conceived situated learning theory which draws together the learner, their activity and their world as 'mutually constitutive'. Learning is a process of participation in 'communities of practice', that is 'legitimate' and at first 'peripheral' but that gradually increases in engagement and complexity. The learning is embodied in the everyday activity of the community and knowledge is co-constructed through participation and social interaction. An expansion of these key terms in situated learning theory are presented in Supplementary Item one $(39,40)$.

Steven et al (41) demonstrated that medical clerkship students learn from real patients by participating in patient care within an educational practice. The students participated in two communities of practice: education and patient care (Figure 2). In some cases, clinical care was provided but no teaching took place and students were unable to learn from the practice, in other cases, students learnt and/or were taught but patient care was not contributory. In education within patient care, students learnt from patient care without intentional teaching. This represents situated learning. In a similar way, undergraduate veterinary students are assigned to various teaching sites (and communities of practice) throughout their clinical training where they are immersed in the work of patient care, to a greater or lesser extent.

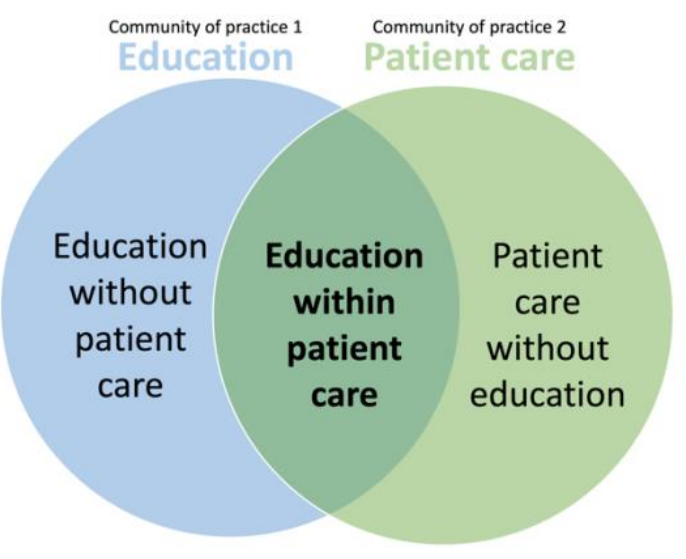

Figure 2: The two communities of practice that medical clerkship students participate in (education and patient care). Situated learning occurs when patient care created learning opportunities, which were enriched when practitioners intentionally supported participants' learning (41).

How clinical students learn from real patients in veterinary workplace settings has not been examined prospectively through the lens of situated learning theory but is discussed from a veterinary perspective by Scholz et al (5). Despite the lack of research, there are facets of veterinary WCT which seem to align well with situated learning theory. First and foremost, veterinary students should broadly be legitimate peripheral participants in a community of practice during WCT (5). Secondly, it is recognised that veterinary students learn from the formal (intended and scheduled), informal 
(opportunistic) and hidden curricula of the veterinary workplace (42-46). The hidden curriculum is the 'underbelly' of practice and training (46), the unwritten information that is tacitly absorbed by students from their environment, particularly what it's like to be a professional in the workplace (enculturation), which is a central tenet of situated learning. Thirdly, students do have increasing levels of responsibility in the workplace as learning occurs and trust develops within the community of practice and they should be genuinely regarded as part of the team. They demonstrate what they have learned through exhibiting competency, externalising rather than internalising knowledge. In an ideal world, veterinary schools would like students' participation to be authentic, and they should take part in all kinds of activity. They should not be 'sequestered' away and left to learn abstract knowledge.

Steven et al (41) describe how practitioners supported students' learning and verbal communication was identified as critical for this. The nature and quality of learning were dependent on clinicians entering a dialogue with students linked to patient care. Scholz et al (5) and King et al (47) also highlight the importance of language in veterinary WCT, which is fundamentally a social enterprise. Participants learn both the technical terminology of the sciences alongside the tacit tone and language required for communicating successfully with clients and colleagues in various contexts, for example on the farmyard, in the consultation room, in theatre or the staff room. The importance of language and the way in which WCT students use it is reflected in the emphasis now placed on communication skills in modern veterinary curricula (48-52).

Situated learning theory provides a detailed model for how students might learn during WCT and there are several facets from which suitable student preparation can be deduced, which are discussed in Table 3. 
Table 3: How can we use situated learning theory to inform valuable student preparedness characteristics for WCT?

\begin{tabular}{|c|c|}
\hline Situated learning theory & Inferred student preparedness characteristics \\
\hline $\begin{array}{l}\text { The student is 'decentralised' in } \\
\text { the community of practice, } \\
\text { where the focus is on the work } \\
\text { to be performed. }\end{array}$ & $\begin{array}{l}\text { Students should understand patient versus student centered education. } \\
\text { They should expect priority to be placed on the work of the practice and } \\
\text { not necessarily on their teaching. } \\
\text { Students need to be prepared to seek the opportunities to learn in all } \\
\text { situations; it is likely that they will not be made explicit. }\end{array}$ \\
\hline $\begin{array}{l}\text { Situated learning is taking part } \\
\text { in all kinds of activity of the } \\
\text { community of practice. }\end{array}$ & $\begin{array}{l}\text { Students should be prepared to 'muck in' with all types of work whilst } \\
\text { participating in WCT and this might include tasks traditionally not } \\
\text { ascribed to veterinarians such as patient restraint or cleaning. Even if not } \\
\text { obviously applicable to their personal learning objectives students should } \\
\text { understand that all kinds of activity enable them to learn about the } \\
\text { culture of the community of practice. Key student attributes for this } \\
\text { could include humility and being a team player. }\end{array}$ \\
\hline $\begin{array}{l}\text { Students require a } \\
\text { 'developmental space' to be } \\
\text { able to learn and develop their } \\
\text { professional identity (53). }\end{array}$ & $\begin{array}{l}\text { The development space constitutes (53): } \\
\text { 1) the attributes of the practice (such as computer system access) - } \\
\text { orientation or transition courses might help students familiarise } \\
\text { themselves with these aspects (54) } \\
\text { 2) productive relationships with other community members - } \\
\text { interpersonal skills are likely to be important } \\
\text { 3) students' state of mind; feeling motivated and self-confident are } \\
\text { emotional pre-requisites for the creation of developmental space and the } \\
\text { subsequent opportunities for personal growth }\end{array}$ \\
\hline $\begin{array}{l}\text { By legitimately contributing to } \\
\text { the community of practice, } \\
\text { students can develop a view of } \\
\text { what the whole enterprise is } \\
\text { about, which can act as a strong } \\
\text { motivator. }\end{array}$ & $\begin{array}{l}\text { Knowing about the community of practice will only be motivating } \\
\text { provided that the student is intrinsically motivated( } 55) \text { i.e. they are } \\
\text { learning in order to become a good veterinarian, as opposed to being } \\
\text { extrinsically motivated to simply pass examinations. }\end{array}$ \\
\hline $\begin{array}{l}\text { Rather than a student/teacher } \\
\text { dyad there is a richly diverse } \\
\text { field of people to learn from in } \\
\text { the community of practice. }\end{array}$ & $\begin{array}{l}\text { Students need to be prepared for interprofessional and peer to peer } \\
\text { education. This may be particularly useful when there is 'benign neglect' } \\
\text { by more experienced and central members of the community of practice. } \\
\text { Students need to appreciate that they can learn from all members of the } \\
\text { professional team. Additionally, 'teachers' fill multiple roles and at times } \\
\text { working and teaching may be in conflict. }\end{array}$ \\
\hline
\end{tabular}




\begin{tabular}{|c|c|}
\hline $\begin{array}{l}\text { Students are peripheral } \\
\text { participants, at first. }\end{array}$ & $\begin{array}{l}\text { Students should have realistic expectations of the peripherality of their } \\
\text { participation as new clinical trainees, and the expected centripetal } \\
\text { 'journey' to the core of the practice where they are competent } \\
\text { veterinarians by the end. The value of the learner to the community of } \\
\text { practice increases as they become more proficient, which should provide } \\
\text { intrinsic reward. }\end{array}$ \\
\hline $\begin{array}{l}\text { Students are treated as } \\
\text { newcomers and not necessarily } \\
\text { novices in the community of } \\
\text { practice. }\end{array}$ & $\begin{array}{l}\text { It is expected that students will enter the community of practice with } \\
\text { some pre-existing knowledge and experience. Students could do well to } \\
\text { consolidate this prior to commencing clinical training. } \\
\text { As newcomers, students can contribute to the community of practice in } \\
\text { meaningful ways. Such responsibility and level of professionalism } \\
\text { expected from students aligns with the Royal College of Veterinary } \\
\text { Surgeons' description of 'nearly professionals' in the workplace (56). }\end{array}$ \\
\hline $\begin{array}{l}\text { Context is an integral part of } \\
\text { practice and its activities (5), } \\
\text { which in turn affects the } \\
\text { affordances (opportunities) for } \\
\text { learning. }\end{array}$ & $\begin{array}{l}\text { Students should approach workplace learning with an appreciation of the } \\
\text { context in which the community of practice is situated. For example: } \\
\text { The seasonal context: the type of work performed at a farm practice will } \\
\text { be dictated somewhat by the time of year, which determines learning } \\
\text { opportunities for students. } \\
\text { The social context: for example, students' knowing which staff member } \\
\text { organises the students into farm vets' cars for visits. } \\
\text { The economic context: the socio-economic background of the practice } \\
\text { and/or clients' insurance status for their animals will impact the } \\
\text { complexity of diagnostics and treatment students will encounter. }\end{array}$ \\
\hline
\end{tabular}




\subsubsection{Cultural Historical Activity Theory.}

Cultural Historical Activity Theory, which is also referred to as activity theory or CHAT, focuses on goal-directed joint activity (21). In this context, activity is not only what and how the subject is performing, but why (termed the object). A key way in which it is different to the other socio-cultural theories is that the intended goal of learning does not align well with Sfard's learning-as-participation, nor learning-as-acquisition metaphors $(38,57)$. Instead, the goal is the expansive transformation of systems; deliberate change that results from tensions arising within a system.

Activity theory takes root in Vygotsky's triad of human-mediated activity in which 'activity' represents the basic unit of analysis (32). The triad consists of a subject (the student, the veterinary surgeon), mediating tools (e.g. patients, diagnostic images) and an object (e.g. preparing future veterinarians, treating patients). In its second-generation form, Engeström describes activity theory as a conceptual framework for describing the interactions of people, the tools that they use and the rules within complex 'activity systems' (58-60). The key terms of activity theory are expanded in Supplementary Item two (58-60).

The third generation of activity theory exists where multiple activity systems interact and compete $(58,61,62)$ (Figure 5). An example would be the activity systems of the classroom-based veterinary school and the clinical teaching facilities that host students. Whilst participants have a shared outcome (veterinary education), the ways in which they mediate their activity and the communities in which they occur are different. Preparedness for the transition from one activity system to the other ('boundary crossing') should consider to what extent students can make sense of the teaching practices used in each system, and identify and react to the changing cultures and rules in their new environment (63). We can consider boundary-crossing artefacts e.g. communication skills practice using actors in the classroom, or clinical skill simulation in the workplace, as potentially useful in preparing for this transition (63).

Another relevant example of two activity systems in competition would be 'student as learner' and 'student as veterinary care provider' systems. When veterinary students are both working and learning in the workplace these activity systems have overlapping but not fully aligned outcomes (Figure 3). An instance of tension would be when a student has the desire to develop a specific skill (object) in order to become a competent veterinarian (outcome), but they do not want to cause the patient or client undue inconvenience by practicing with them (a competing object in a different activity system, with the outcome of patient care) $(34,62)$. Simultaneously the student may feel pressure to display their competence in the skill to the clinical supervisor to achieve a good assessment result (another outcome).

(Figure 3 withdrawn due to licensing terms, the authors would direct readers to the original article)

Figure 3: Adapted with permission from Larsen et al, (2019) (61) for the veterinary WCT context. The clinical veterinary student in the workplace is part of several activity systems, between which there 
may be interaction or tensions and competing outcomes. (RCVS = Royal College of Veterinary Surgeons.)

However, these tensions are creative forces for change (64). To overcome them, new ways of acting or new objects can be developed in the workplace and this process is termed expansive learning (65). In the above example, the clinical supervisor could help the student to identify amenable patients to practice with and facilitate getting consent.

Using written learning goals for clinical workplace training has been described as a tool to overcome tensions in the medical workplace $(61,62)$ and several desirable preparedness characteristics could be assumed from this work. Larsen et al identified that student engagement with and commitment to goals were important and that students should understand that they can use learning goals to negotiate the demands faced in the workplace. This may include prioritising who or what they observe and take part in, reflecting on how their time is best used and acknowledgement that a degree of proactivity is required to create opportunities for participation. However, the vicissitude of daily practice needs to be acknowledged and a realisation that the learning goals of the student will not necessarily match the needs of the patients that walk in through the door. Some supervisors identified broader goals to be useful; these were seen as tools for leveraging greater learning opportunities because as they fit many more scenarios.

\subsubsection{Experience Based Learning (ExBL).}

Dornan et al explored the pedagogic principles that underlie rotation based medical clerkships (analogous to veterinary WCT), and from it developed Experience Based Learning (ExBL) theory (Figure 4) $(66,67)$. The theory clearly draws on the higher communities of practice theory from Lave and Wenger (39) but is applied to the clinical setting resulting in a middle-range theory grounded in empirical findings.

(Figure 4 withdrawn due to licensing terms, the authors would direct readers to the original article)

Figure 4: Experience-based learning theory adapted with permission from Dornan et al, (2014) (66).

The theory states that medical students learn during clerkships as a result of 'supported participation in practice' $(66,68)$. Participation is embedded within triadic relationships between the student, clinical supervisors, and their patients in authentic workplaces. Within the triad, the student can have an observatory (passive or active) or actor-like (in rehearsal or in performance) role (Figure 4). Unlike in Lave and Wenger's (39) communities of practice, teaching is observable and does contribute to ExBL, however, it is not a central or defining feature. Participation is always supported, and it is provided in three ways: pedagogic, affective, and organisational support (Figure 4). Participation is rooted in 'real patient learning', a critical process that results in both practical (proficiency) and affective outcomes, but it is also a learning outcome in itself. These outcomes contribute to professional identity development. How these outcomes can be used to inform the preparation of veterinary students for 'supported participation in practice' is discussed in Table 4. 
Table 4: How can experience based learning (ExBL) theory outcomes be used to inform valuable preparedness characteristics for veterinary WCT?

\begin{tabular}{|c|c|c|}
\hline \multicolumn{2}{|c|}{ Learning outcome $(41,67)$} & \multirow{2}{*}{ 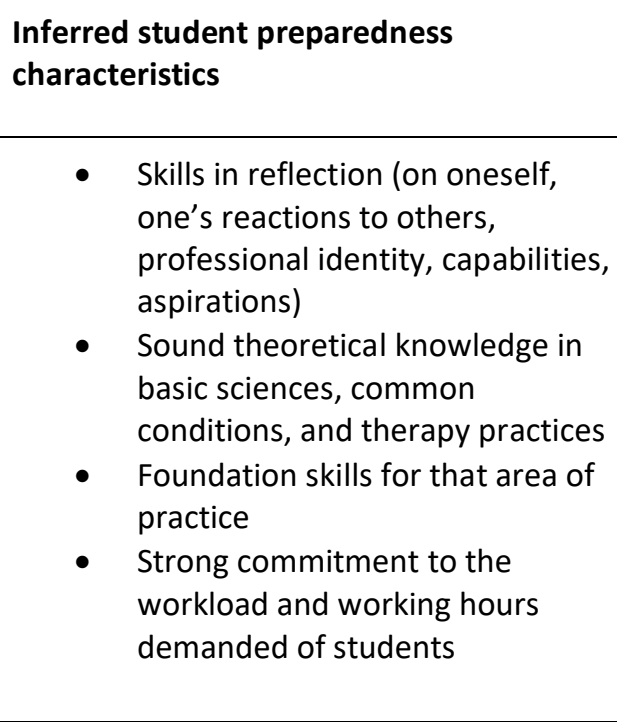 } \\
\hline $\begin{array}{l}\text { Real patient } \\
\text { learning }\end{array}$ & $\begin{array}{l}\text { - A reflective process } \\
\text { - } \quad \text { Results from the interaction with real patients } \\
\text { Involves linking existing knowledge to } \\
\text { memorable patients i.e., restructuring, } \\
\text { consolidating, reinforcing, and contextualising } \\
\text { prior learning } \\
\text { - Involves integrating knowledge with attitudes } \\
\text { and skills } \\
\text { - Contributes to a students' ability to care for a } \\
\text { patient } \\
\text { Allows students to gain the quantity of } \\
\text { experience and hours of supervision to } \\
\text { become competent }\end{array}$ & \\
\hline $\begin{array}{l}\text { Affective } \\
\text { learning }\end{array}$ & $\begin{array}{l}\text { - Includes students' motions, moods, state of } \\
\text { mind } \\
\text { - Can be directed at oneself or towards others } \\
\text { - Positive: a sense of belonging, increasing } \\
\text { comfort, legitimacy, coping with uncertainty, } \\
\text { sense of satisfaction and reward, empathy } \\
\text { and compassion } \\
\text { - } \quad \text { Negative: illegitimacy, discomfort assuming } \\
\text { the role of a student doctor, loss of } \\
\text { confidence, demotivation, frustration, anxiety } \\
\text { - Negative emotions were often associated } \\
\text { with transitions when students struggled to } \\
\text { adjust - this has potentially important } \\
\text { implications for preparedness }\end{array}$ & $\begin{array}{l}\text { - Ability to recognise and respond } \\
\text { appropriately to negative moods } \\
\text { states } \\
\text { - Ability to recognise and respond } \\
\text { appropriately to negative } \\
\text { emotions directed at the student } \\
\text { (being non-judgmental, } \\
\text { respectful, empathetic) } \\
\text { - } \quad \text { Recognising boundaries and limits } \\
\text { - Strong motivation, demonstrating } \\
\text { a desire to learn, enthusiasm and } \\
\text { interest in the training }\end{array}$ \\
\hline $\begin{array}{l}\text { Practical } \\
\text { learning } \\
\text { (proficiency) }\end{array}$ & $\begin{array}{l}\text { - Learning how to practice - understanding it, } \\
\text { rather than simply knowing about it } \\
\text { Includes more traditionally recognised } \\
\text { learning outcomes - knowledge and practical } \\
\text { skills } \\
\text { - Organisational aspects of practice } \\
\text { - How to manage learning - identifying } \\
\text { individual limits and then establishing } \\
\text { learning needs, and where to find then use } \\
\text { resources }\end{array}$ & $\begin{array}{l}\text { - Knowledge of other professions } \\
\text { and their roles in the shared } \\
\text { workspace } \\
\text { - Some understanding of the } \\
\text { department/ organisation where } \\
\text { they will be undertaking training } \\
\text { - Ability to adhere to workplace } \\
\text { standard operating procedures } \\
\text { and policies } \\
\text { Knowledge of how to access } \\
\text { information when a gap in } \\
\text { knowledge is identified } \\
\text { - Understanding of their own } \\
\text { learning style }\end{array}$ \\
\hline
\end{tabular}




\subsubsection{Organisational socialisation theory.}

Organisational socialisation theory describes the way in which newcomers move from being organisational outsiders to organisational insiders (69). It incorporates the process by which new members learn the knowledge, skills and behaviours they need to succeed in their new environment. It is distinct from the process of occupational socialisation which describes professional identity formation. Organisational socialisation theory is important to consider because students are embedded in social organisations during WCT and the transition into it reflects the effectiveness of the programme in preparing students.

Organisational socialisation theory has been utilised by Atherley et al (36) to explore how medical students transition within their rotational clinical training, additionally it has been applied to nursing graduates entering the clinical workplace (70). The first phase of the theory has three components (69): newcomer characteristics, newcomer behaviours and organisational efforts. This is followed by an adjustment phase, leading to newcomer outcomes (Figure 5).

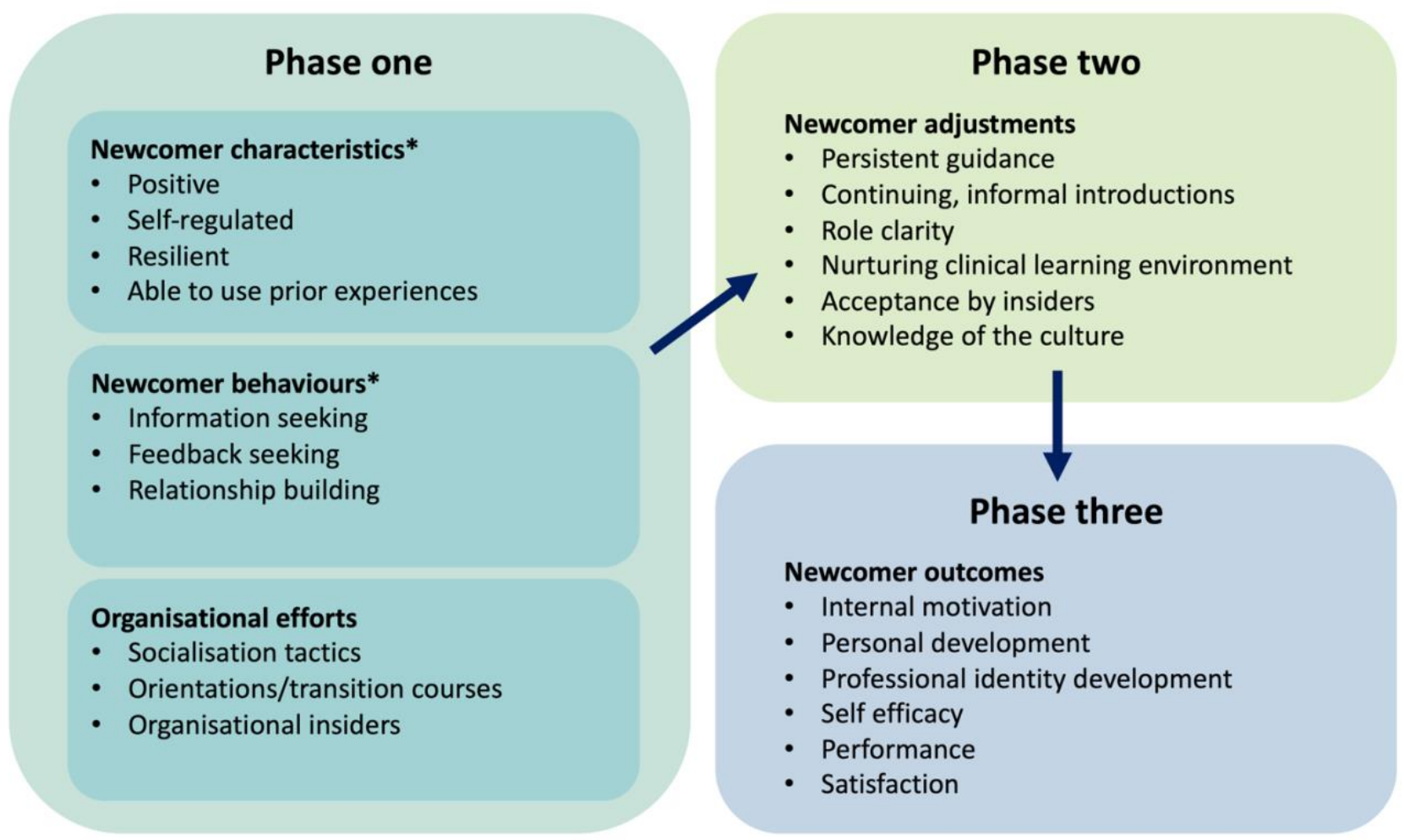

Figure 5: Adapted from Atherley et al, (2016) (36). Organisational socialisation theory. (* Newcomer characteristics and behaviours align particularly well to preparedness for WCT).

Newcomer characteristics and behaviours directly align with preparedness for entering the workplace. Through student focus groups and open-ended written questions, Atherley et al (36) found that students recognised the need to commence a placement with proactivity, positivity and the ability to build productive relationships. Students were required to ignore the reputation that preceded the rotation (via the 'student grapevine' (35)) to achieve this, or risk anxiety prohibiting learning. Peer-to-peer preparation for veterinary WCT has also been identified as conceivably 
problematic given the potential for the transmission of misconceptions (34). Many students were concerned about their role as part of the medical team and clarification would have been useful in preparation. Only a few students looked forward to feedback-seeking but those that did thought it would be useful in the transition. It was also suggested that targeting skills such as self-regulated learning (goal-setting, self-monitoring and self-reflection (71)) and resilience in the pre-clinical phase may prove useful in developing proactivity and feedback-seeking behaviour.

\subsubsection{Billet's theory of workplace affordances and individual engagements.}

Billet's theory of workplace affordances and individual engagements identifies the factors that shape learning in workplaces (72-74). It is centered on co-participation, and the duality of how the workplace invites access to activities and guidance (workplace affordances) but also how individuals elect to participate in what the workplace affords (individual engagements).

King et al (47) developed a constructivist grounded theory to understand how veterinary students interact in the workplace and Billet's workplace affordances and individual engagements provided a conceptual orientation for the work. The resulting theory 'Learning to Interact and Interacting to Learn' (LIIL) has a central concept of harnessing dialogue. Students came to understand that the way in which they engaged in dialogue influenced three inter-related processes 1) contributing to the daily functioning of the workplace, 2) the impressions that others had of them and 3) learning in the moment, acquiring specific skills or knowledge whilst working. They established that some students had to learn to interact more effectively, to be able to learn from interactions. Preparation of veterinary students for learning in the workplace could therefore include building social discourse awareness to enable students to perceive how best to find learning opportunities through interaction.

The work by King et al shines a light on the importance of learner agency; how veterinary students elect to engage with workplace activities. Billet explains that learning new knowledge is an active, demanding process; individuals must be prepared to engage actively and deliberately seek to improve performance. This process includes self-directed learning, interacting with others, objects, and artefacts, and perceptively seeking clues from the social and physical environment for arising opportunities, and then monitoring progress during task completion.

Additionally, veterinary students might elect to engage actively in some components of activities but less actively (and even resentfully) in others, often simultaneously. It is also likely that individuals' interests and priorities will mediate their participation in work. This is perhaps enhanced by the fact that veterinary students, at the time of WCT, are likely to have species-specific career aspirations, which according to Billet's theory may influence the effort they expend on each rotation. Given that full-bodied engagement by individuals is likely to be required to develop robust vocational practices, we can infer that veterinary students should engage with all opportunities with equal enthusiasm and endeavour, despite any influence of their individual interests. 
No single theory of learning can adequately explain the process of WCT in its entirety or in all its detail. However, by considering a number of theories, principles and models a framework of learning can be constructed, which can be used to inform different components of WCT preparedness and as a reference for discussion. We should recognise that these theories describe what should or could happen in ideal circumstances, and it cannot be assumed that every clinical training experience will be like this. Extensive research using objectivist deductivist approaches and theories in conceptual frameworks will be required to confirm how well, or how poorly, the learning theories approximate WCT in reality (75). Given the confusion in terminology around, and lack of evidence supporting, individual student learning styles (76) the impact of students' preferences for learning have not been considered here.

It is intuitive that WCT is best understood from a socio-cultural perspective. There is very little published putting these theories to work in veterinary education and much of the content discussed here draws on observations and analysis of medical clerkships. It is reasonable to deduce that similarly veterinary WCT is shaped by experience as a peripheral participant within a community of practice. Students can be seen as boundary crossers who are engaged with the objects of two activity systems (student-as-learner and student-as-worker). Through observing, rehearsing and performing students achieve affective and practical learning outcomes alongside real patient learning. Organisational socialisation theory suggests that newcomer characteristics, behaviours and adjustments could help students to transition to workplace learning proficiently. Some aspects of cognitivism are also instinctively important for veterinary clinical trainees: grasping threshold concepts such as patient-centeredness and uncertainty and risk in decision making, reflecting in and on action and conducting their training in an andragogical manner.

Being prepared for WCT and the student's ability to learn is not limited by their actual development level (32); students can possess sufficient prior knowledge but fail to learn in workplaces (77). This is because competence in WCT is likely to be highly contextualised (78); it is fundamentally affected by the activity, organisational practices and culture of that particular workplace (79). Preparedness is also individualised and fluctuates over time (80). For these reasons, it is not possible to be fully prepared for a transition into WCT, and it should be viewed as a 'critically intensive learning period' instead (79). However, by understanding how students learn from WCT using learning theory we can deduce how students could be placed in the best position to learn from those experiences i.e., how they can best be prepared.

We propose that a conceptual framework, the "preparedness toolkit", could be a useful way to think about preparedness and it is stated in Figure 6. Bordage explains that "conceptual frameworks represent ways of thinking about a problem or a study, or ways of representing how complex things work. They can come from theories, models or best practices." (13) (pg 312). The "preparedness toolkit" contains tools derived from the learning theories explored in this paper, which if possessed 
by the veterinary student, will assist them in learning and working at the expected level during WCT whilst negotiating the critically intensive learning period. In other words, it will facilitate their competency (actual performance). This conceptual framework is only the start of a scholarly conversation; it can be used in future research to support data collection and analysis about student preparedness for WCT. This research will be theoretically grounded in a novel way; drawing on many theories to produce a conceptual framework of preparedness for WCT de novo. 
Figure 6: The veterinary clinical trainee preparedness toolbox contains the preparedness characteristics, derived from an understanding of relevant learning theory, which could be utilised to engage with, and learn from, the veterinary workplace by undergraduate veterinary students. (LIIL = Learning to Interact, Interacting to Learn).

Kolb's

learning

cycle

Reflective

learning

theory

Andragogy

Threshold concepts

Vygotsky's

proximal

development

Situated

learning theor

Activity theory

Experience based learnin

Organisationa socialisation

theory

Billet and LIIL

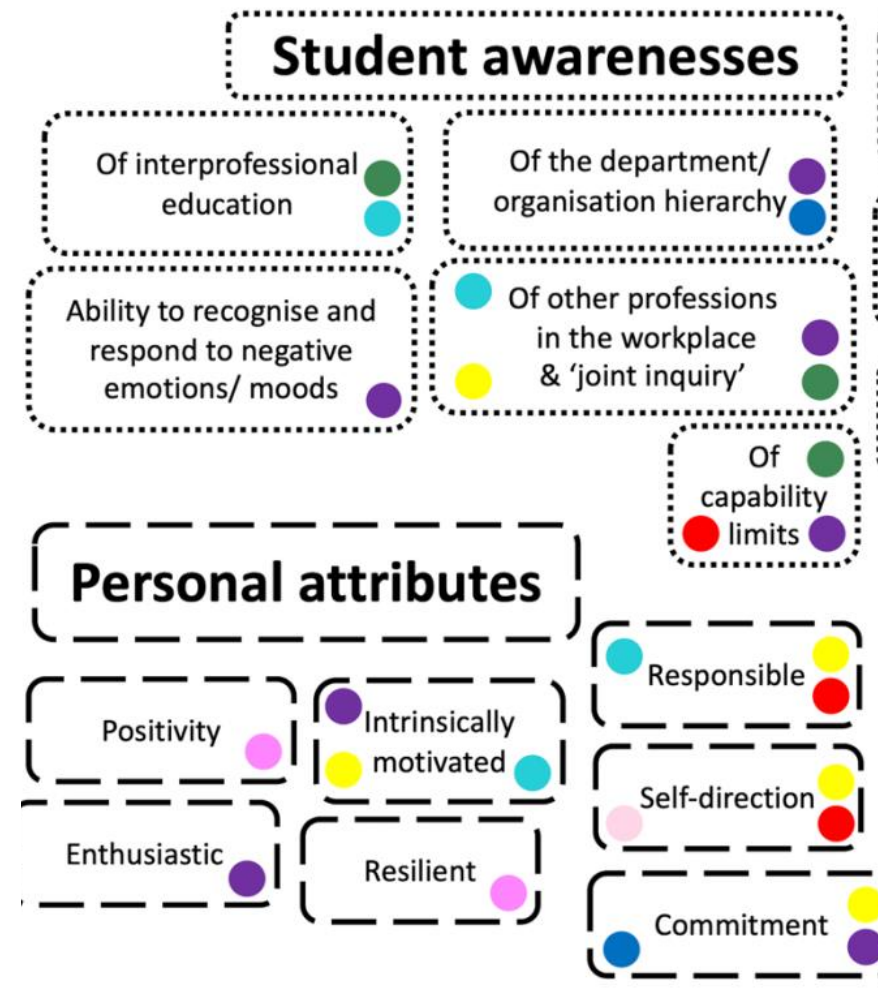

Of possible conflict between student vs. patient centered activity systems

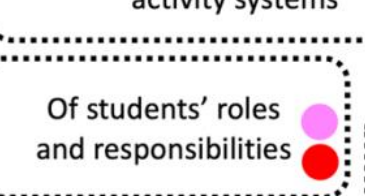

and responsibilities

Of the context of each workplace

Of language of the workplace

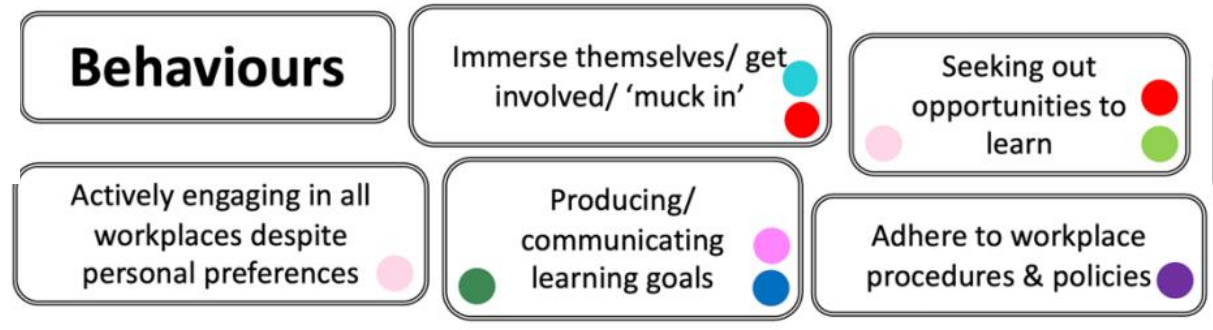

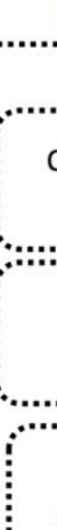

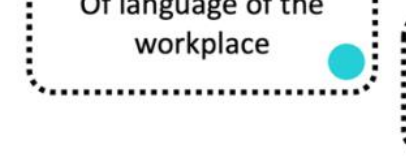

0

Of the hidden
curriculum

::::::::::::::::

Of how learning

opportunities can

present themselves

0

\section{Knowledge \& skills}

Common therapeutic practices

Threshold concepts (neurology \& pharmacology?)
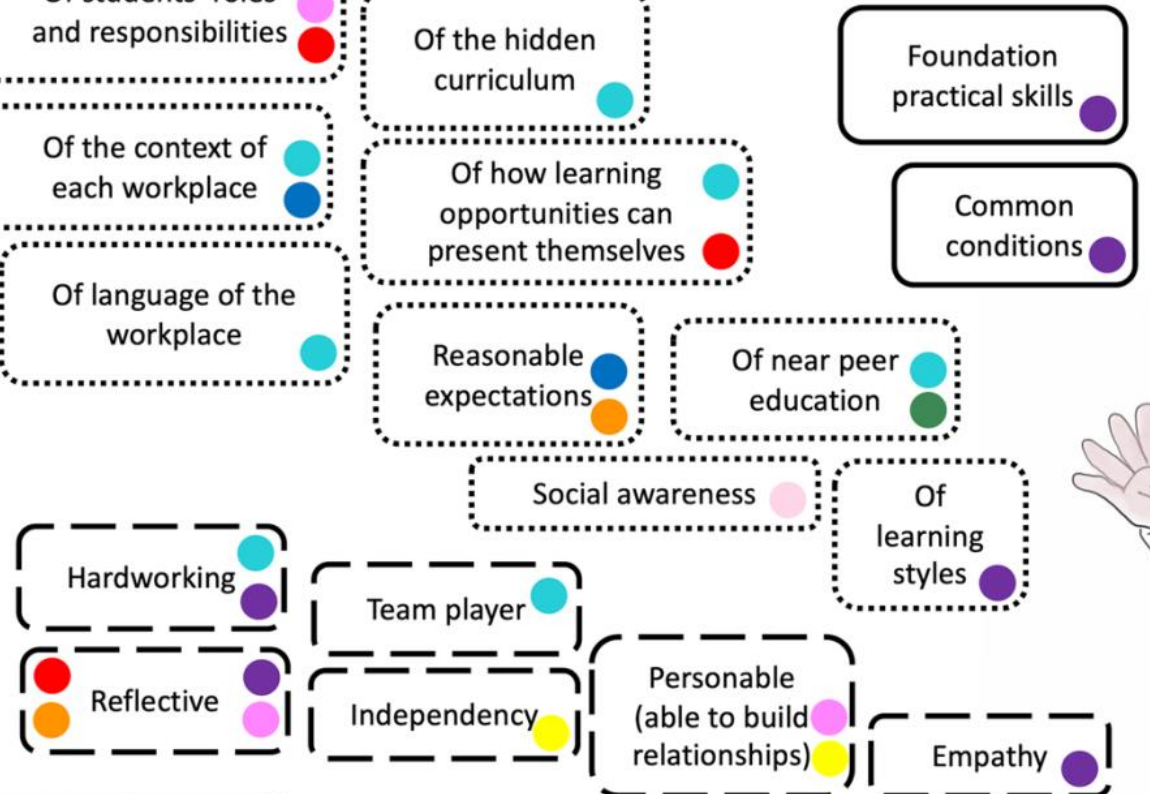

Basic sciences

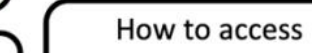

Common information to fill conditions knowledge gaps

pectations
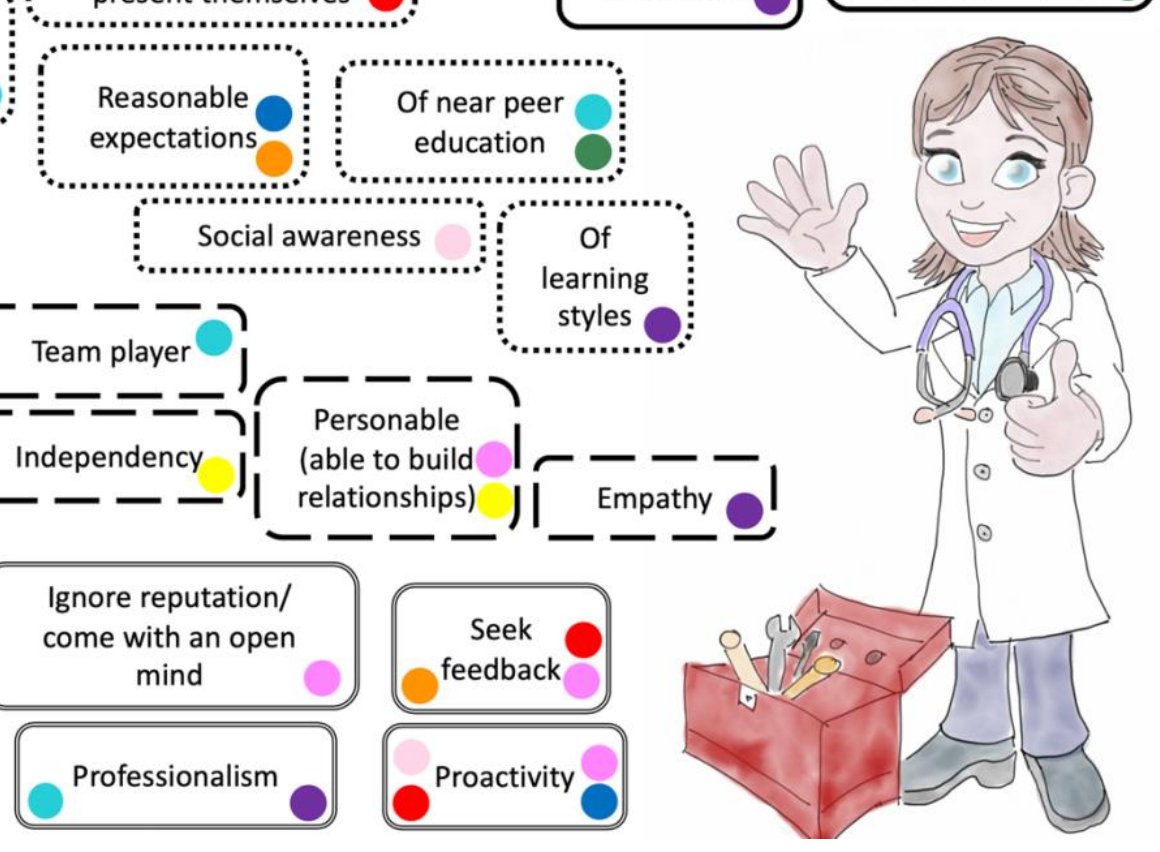


\section{Supplementary information}

\subsection{Key terms in situated learning theory}

\section{Communities of practice}

- Communities of practice describes a set of relationships between people and their activities

- It does not necessarily imply co-presence or socially visible boundaries

- Participants in a community of practice have a shared understanding about what they are trying to achieve through work

- Commnities of practice have 'reproduction cycles': the time taken from being newcomer to a core member or 'old timer'

- In the context of veterinary education and WCT, the community of practice could be applied to the individual practice that the student is placed in, or to the veterinary profession itself

\section{Situated learning}

- An aspect of all activity in the community of practice

- Decoupled from teaching, it happens whether there's educational intention or not

- The student is 'decentralised' - teaching is not the central motive of the community of practice, the work is

\section{Legitimate participation}

- Legitimate participation describes how the learner engages authentically in the daily function of the community of practice

- Authentic activity is a way for students to not only learn how to be a veterinary surgeon, but they also gain access to what it's like to be one. Learning in the community of practice involves belonging, becoming and identity.

-Students need access to ongoing activity, 'old timers', resources and opportunity for situated learning to take place.

-Activities must be non-menial and transparent so that learners acquire knowledge of how and why activities are performed

- If legitimate participation fails, students become 'sequestered'. This promotes the formation of abstract knowledge with little context and disconnection from the practice culture

- Learning is externalised through participation, this reflects assessment methods where students demonstrate competency

- Language is important; learning involves learning to talk in the manner of full participants, giving the student face validity

\section{Peripheral participation}

- Newcomers will have an observational outlook post at first, but learning still occurs through being absorbed in the culture of the practice

- As peripheral participants, students may learn activities of the community of practice in the incorrect order, as less complex, vital or risky tasks are learned first. As an example, students may learn to make skin incisions or suturing before performing difficult surgeries 


\subsection{Key terms in Cultural Historical Activity Theory (CHAT)}

Outcome

- The overarching common goal of the activity system for example, patient care or student education

\section{Objects}

- The immediate purposes of actions which lead to the outcome. Examples might include to improve history taking (object) to provide patient care (outcome)

\section{Divison of labour}

- Objects are achieved through the division of labour which is related to the social hierarchy of the community

- For example, the anaesthetist prevents pain and consciousness, the surgeon performs the operation whilst the student learns and the nurse assists. These are separate objects of a shared activity system, achieving an outcome

\section{Subjects}

- The individual members of the community engaged in the activities

\section{Community}

- The community represents the social context of the activity system

\section{Rules}

- The rules are the conventions (workplace knowledge), guidelines or rules that regulate the activities

\section{Tools}

- Tools are used by the subjects. They include symbolic artifacts such as the knowledge, competencies and specialist terminology of the community of practice along with the physical tools used to perform the activities such as patients, stethoscopes, diagnostic images, patient management systems or charts 
The authors declare that the research was conducted in the absence of any commercial or financial relationships that could be construed as a potential conflict of interest.

\section{Author Contributions}

JR, SP, PC and KJ contributed to the conception of the manuscript. JR wrote the manuscript. All authors contributed to manuscript revision, read, and approved the submitted version.

\section{$8 \quad$ Funding}

Jennifer Routh's PhD research, to which this work contributes, is sponsored by the Longhurst Legacy (University of Surrey)

\section{Acknowledgements}

Figure 5 (modified from Atherley et al, 2016): "This is an open access article distributed under the terms of the Creative Commons CC BY license, which permits unrestricted use, distribution, and reproduction in any medium, provided the original work is properly cited. You are not required to obtain permission to reuse this article." 
1. Billay D, Myrick F. Preceptorship: An integrative review of the literature. Nurse Educ Pract (2008) 8(4):258-66. doi: https://doi.org/10.1016/j.nepr.2007.09.005.

2. Shipengrover JA, James PA. Measuring instructional quality in community-orientated medical education: looking into the black box. Med Educ (1999) 33(11):846-53. doi: 10.1046/j.13652923.1999.00480.x.

3. Dale VHM, Sullivan M, May SA. Adult learning in veterinary education: Theory to practice. J Vet Med Educ (2008) 35(4):581-8. doi: 10.3138/jvme.35.4.581.

4. Parkinson TJ, St. George AM. Are the Concepts of Andragogy and Pedagogy Relevant to Veterinary Undergraduate Teaching? J Vet Med Educ (2003) 30(3):247-53. doi: 10.3138/jvme.30.3.247.

5. Scholz E, Trede F, Raidal SL. Workplace Learning in Veterinary Education: A Sociocultural Perspective. J Vet Med Educ (2013) 40(4):355-62. doi: 10.3138/jvme.0113-015R.

6. Meehan MP, Menniti MF. Final-year veterinary students' perceptions of their communication competencies and a communication skills training program delivered in a primary care setting and based on Kolb's Experiential Learning Theory. J Vet Med Educ (2014) 41(4):371-83. Epub 2014/08/26. doi: 10.3138/jvme.1213-162R1. PubMed PMID: 25148880.

7. Barron D, Khosa D, Jones-Bitton A. Experiential Learning in Primary Care: Impact on Veterinary Students' Communication Confidence. Journal of Experiential Education (2017) 40(4):349-65. doi: 10.1177/1053825917710038.

8. King E. Learning to interact and interacting to learn: a grounded theory of clinical workplace learning for diverse cohorts: The University of Queensland (2020).

9. Moore DA, Leamon MH, Cox PD, Servis ME. Teaching Implications of Different Educational Theories and Approaches. J Vet Med Educ (2002) 29(2):117-23. doi: 10.3138/jvme.29.2.117.

10. Schoenfeld-Tacher R, Baker HJ. Educational Theory and Practice. J Vet Med Educ (2013) 40(2):94-5. doi: 10.3138/jvme.0313-051. PubMed PMID: 23697540.

11. Kaufman DM. Teaching and Learning in Medical Education: How Theory can Inform Practice. In: Swanwick T, Forrest K, O’Brien B, editors. Understanding Medical Education: Evidence, Theory and Practice. Third ed. Hoboken, NJ: Wiley-Blackwell (2019). p. 37-69.

12. Burford B, Vance G. When I say ... preparedness. Med Educ (2014) 48(9):849-50. doi: 10.1111/medu.12427.

13. Bordage G. Conceptual frameworks to illuminate and magnify. Med Educ (2009) 43(4):312-9. Epub 2009/04/02. doi: 10.1111/j.1365-2923.2009.03295.x. PubMed PMID: 19335572. 
14. Teunissen PW. Trust your struggle. Perspectives on Medical Education (2016) 5(2):69-70. doi: 10.1007/s40037-016-0259-3.

15. Kolb DA. Experiential learning : experience as the source of learning and development. Englewood Cliffs, N.J.: Prentice Hall (1984).

16. Knowles MS. The modern practice of adult education: from pedagogy to andragogy. Rev. \& updated. ed. Englewood Cliffs, N.J: Cambridge Adult Education (1980).

17. Schön DA. Educating the reflective practitioner : [toward a new design for teaching and learning in the professions]. San Francisco: Jossey-Bass (1987).

18. Warman SM, Laws EJ, Crowther E, Baillie S. Initiatives to improve feedback culture in the final year of a veterinary program. J Vet Med Educ (2014) 41(2):162-71. Epub 2014/04/02. doi: 10.3138/jvme.1013-142R. PubMed PMID: 24686719.

19. Greenberg L, Blatt B. Perspective: Successfully Negotiating the Clerkship Years of Medical School: A Guide for Medical Students, Implications for Residents and Faculty. Acad Med (2010) 85(4):706-9. doi: 10.1097/ACM.0b013e3181d2aaf2. PubMed PMID: 00001888-201004000-00038.

20. Pew National Veterinary Education Program. Future directions for veterinary medicine: The Pew report Pew National Veterinary Education Program. The Canadian Veterinary Journal (1989) 30(6):472-6. PubMed PMID: 17423343.

21. Yardley S, Teunissen PW, Dornan T. Experiential learning: AMEE Guide No. 63. Med Teach (2012) 34(2):e102-15. Epub 2012/02/01. doi: 10.3109/0142159x.2012.650741. PubMed PMID: 22289008.

22. Merriam SB. Andragogy and Self-Directed Learning: Pillars of Adult Learning Theory. New Directions for Adult and Continuing Education (2001) 2001(89):3-14. doi: 10.1002/ace.3.

23. Matthew SM, Taylor RM, Ellis RA. Students' experiences of clinic-based learning during a final year veterinary internship programme. Higher Education Research \& Development (2010) 29(4):389-404. doi: 10.1080/07294361003717903.

24. Matthew SM, Ellis RA, Taylor RM. Evaluating the Quality of Veterinary Students' Experiences of Learning in Clinics. J Vet Med Educ (2017) 44(2):369-80. Epub 2017/04/05. doi: 10.3138/jvme.0516-094R. PubMed PMID: 28375072.

25. Meyer J, Land R. Threshold Concepts and Troublesome Knowledge (2): Epistemological Considerations and a Conceptual Framework for Teaching and Learning. Higher Education (2005) 49(3):373-88.

26. Meyer J, Land R. Threshold concepts and troublesome knowledge: Linkages to ways of thinking and practising within the disciplines. In: Rust C, editor. Improving Student Learning: Improving Student Learning Theory and Practice - Ten Years On. Oxford: Oxford Centre for Staff and Learning Development (2003).

27. Rhind SM, Warman S, Paterson J, Hughes KJ, Hammond J, editors. Short Communication: An Exploration of Threshold Concepts in the Veterinary Curriculum. VetEd Symposium; 2014; Bristol. 
28. Bhat C, Burm S, Mohan T, Chahine S, Goldszmidt M. What trainees grapple with: a study of threshold concepts on the medicine ward. Med Educ (2018) 52(6):620-31. doi: 10.1111/medu.13526.

29. Neve H, Wearn A, Collett T. What are threshold concepts and how can they inform medical education? Med Teach (2016) 38(8):850-3. doi: 10.3109/0142159X.2015.1112889.

30. Neve H, Lloyd H, Collett T. Understanding students' experiences of professionalism learning: a 'threshold' approach. Teaching in Higher Education (2017) 22(1):92-108. doi: 10.1080/13562517.2016.1221810.

31. Gaunt T, Loffman C. When I say... threshold concepts. Med Educ (2018) 52(8):789-90. doi: https://doi.org/10.1111/medu.13537.

32. Vygotsky LS. Mind in society: The development of higher psychological processes: Harvard university press (1980).

33. Morris C. Work-based learning. In: Swanwick T, Forrest K, O’Brien B, editors. Understanding Medical Education: Evidence, Theory and Practice. Third ed. Hoboken, NJ: Wiley-Blackwell (2019). p. 163-77.

34. Magnier K, Wang R, Dale VHM, Murphy R, Hammond RA, Mossop L, et al. Enhancing clinical learning in the workplace: a qualitative study. The Veterinary record (2011) 169(26):682-. Epub 2011/11/16. doi: 10.1136/vr.100297. PubMed PMID: 22090156.

35. Masters DE, O'Brien BC, Chou CL. The third-year medical student "grapevine": managing transitions between third-year clerkships using peer-to-peer handoffs. Acad Med (2013) 88(10):1534-8. Epub 2013/08/24. doi: 10.1097/ACM.0b013e3182a36c26. PubMed PMID: 23969370.

36. Atherley AE, Hambleton IR, Unwin N, George C, Lashley PM, Taylor CG, Jr. Exploring the transition of undergraduate medical students into a clinical clerkship using organizational socialization theory. Perspectives on medical education (2016) 5(2):78-87. doi: 10.1007/s40037-015-0241-5. PubMed PMID: 26951164.

37. Royal Veterinary College. Online Induction Video Educational Resource (OLIVER) (2011) [cited 2021 15/01/2021]. Available from: https://oliver.live.ac.uk.

38. Sfard A. On Two Metaphors for Learning and the Dangers of Choosing Just One. Educational Researcher (1998) 27(2):4-13. doi: 10.2307/1176193.

39. Lave J, Wenger E. Situated learning: Legitimate peripheral participation: Cambridge university press (1991).

40. Wenger E. Communities of practice : learning, meaning, and identity. Cambridge: Cambridge University Press (1998).

41. Steven K, Wenger E, Boshuizen H, Scherpbier A, Dornan T. How Clerkship Students Learn From Real Patients in Practice Settings. Acad Med (2014) 89(3):469-76. doi: 10.1097/acm.0000000000000129. PubMed PMID: 00001888-201403000-00028. 
42. Mossop L, Dennick R, Hammond R, Robbé I. Analysing the hidden curriculum: use of a cultural web. Med Educ (2013) 47(2):134-43. doi: 10.1111/medu.12072.

43. Gaufberg EH, Batalden M, Sands R, Bell SK. The hidden curriculum: what can we learn from third-year medical student narrative reflections? Acad Med (2010) 85(11):1709-16. Epub 2010/10/01. doi: 10.1097/ACM.0b013e3181f57899. PubMed PMID: 20881818.

44. Roder CA, May SA. The Hidden Curriculum of Veterinary Education: Mediators and Moderators of Its Effects. J Vet Med Educ (2017) 44(3):542-51. doi: 10.3138/jvme.0416-082. PubMed PMID: 28876989.

45. Whitcomb TL. Raising Awareness of the Hidden Curriculum in Veterinary Medical Education: A Review and Call for Research. J Vet Med Educ (2014) 41(4):344-9. doi: 10.3138/jvme.0314-032R1. PubMed PMID: 25335646.

46. Hafferty FW. Beyond curriculum reform: confronting medicine's hidden curriculum. Acad Med (1998) 73(4):403-7. Epub 1998/05/15. doi: 10.1097/00001888-199804000-00013. PubMed PMID: 9580717.

47. King E, Turpin M, Green W, Schull D. Learning to interact and interacting to learn: a substantive theory of clinical workplace learning for diverse cohorts. Advances in Health Sciences Education (2019) 24(4):691-706. doi: 10.1007/s10459-019-09891-8.

48. Shaw JR. Evaluation of communication skills training programs at North American veterinary medical training institutions. J Am Vet Med Assoc (2019) 255(6):722-33. doi: 10.2460/javma.255.6.722.

49. Englar RE. A Novel Approach to Simulation-Based Education for Veterinary Medical Communication Training Over Eight Consecutive Pre-Clinical Quarters. J Vet Med Educ (2017) 44(3):502-22. Epub 2017/09/07. doi: 10.3138/jvme.0716-118R1. PubMed PMID: 28876987.

50. Englar RE. Tracking Veterinary Students' Acquisition of Communication Skills and Clinical Communication Confidence by Comparing Student Performance in the First and Twenty-Seventh Standardized Client Encounters. J Vet Med Educ (2019) 46(2):235-57. Epub 2018/10/05. doi: 10.3138/jvme.0917-117r1. PubMed PMID: 30285598.

51. Stevens BJ, Kedrowicz AA. Evaluation of fourth-year veterinary students' client communication skills: Recommendations for scaffolded instruction and practice. J Vet Med Educ (2018) 45(1):85-90. doi: 10.3138/jvme.0816-129r1.

52. Sheats MK, Hammond S, Kedrowicz AA. Analysis of final year veterinary students' telephone communication skills at a veterinary teaching hospital. Veterinary Sciences (2018) 5(4). doi: 10.3390/vetsci5040099.

53. Van der Zwet J, Zwietering P, Teunissen P, Van der Vleuten C, Scherpbier A. Workplace learning from a socio-cultural perspective: creating developmental space during the general practice clerkship. Advances in Health Sciences Education (2011) 16(3):359-73. 
54. O'Brien BC, Poncelet AN. Transition to clerkship courses: preparing students to enter the workplace. Acad Med (2010) 85(12):1862-9. Epub 2010/10/28. doi: 10.1097/ACM.0b013e3181fa2353. PubMed PMID: 20978432.

55. Ryan RM, Deci EL. Intrinsic and Extrinsic Motivations: Classic Definitions and New Directions. Contemp Educ Psychol (2000) 25(1):54-67. doi: https://doi.org/10.1006/ceps.1999.1020.

56. Royal College of Veterinary Surgeons. Consultation on extra-mural studies in the veterinary undergraduate curriculum (2009) [cited 2020 01/10/2020]. Available from: https://www.rcvs.org.uk/document-library/ems-consultation-paper/.

57. Morris C. From time-served apprenticeship to time-measured training: new challenges for postgraduate medical education: University of London (2011).

58. Engeström Y. Expansive Learning at Work: Toward an activity theoretical reconceptualization. Journal of Education and Work (2001) 14(1):133-56. doi: 10.1080/13639080020028747.

59. Engeström Y. Learning by expanding: An activity. Theoretical Approach to Develomental ResearchHelsinki: Orienta-Konsultit (1987).

60. Engeström Y. Innovative learning in work teams: Analyzing cycles of knowledge creation in practice. In: Engeström Y, Miettinen R, Punamäki R-L, editors. Perspectives on Activity Theory. First ed. Cambridge, UK: Cambridge University Press (1999). p. 377 - 404.

61. Larsen DP, Nimmon L, Varpio L. Cultural Historical Activity Theory: The Role of Tools and Tensions in Medical Education. Acad Med (2019) 94(8):1255. doi: 10.1097/acm.0000000000002736. PubMed PMID: 00001888-201908000-00044.

62. Larsen DP, Wesevich A, Lichtenfeld J, Artino Jr AR, Brydges R, Varpio L. Tying knots: an activity theory analysis of student learning goals in clinical education. Med Educ (2017) 51(7):687-98.

63. Morris C. From classroom to clinic: an activity theory perspective. In: Cook V, Daly C, Newman M, editors. Work-based Learning in Clinical Settings: Insights from Socio-cultural Perspectives. First ed. London, UK: Radcliffe Publishing Ltd (2012). p. 85-102.

64. Morris C, Reid A-M, Ledger A, Teodorczuk A. Expansive learning in medical education: Putting Change Laboratory to work. Med Teach (2020):1-6. doi: 10.1080/0142159X.2020.1796948.

65. Engeström $Y$, Sannino A. Studies of expansive learning: Foundations, findings and future challenges. Educational Research Review (2010) 5(1):1-24. doi: https://doi.org/10.1016/j.edurev.2009.12.002.

66. Dornan T, Tan N, Boshuizen H, Gick R, Isba R, Mann K, et al. How and what do medical students learn in clerkships? Experience based learning (ExBL). Advances in Health Sciences Education (2014) 19(5):721-49. doi: 10.1007/s10459-014-9501-0. 
67. Dornan T, Conn R, Monaghan H, Kearney G, Gillespie H, Bennett D. Experience Based Learning (ExBL): Clinical teaching for the twenty-first century. Med Teach (2019) 41(10):1098-105. doi: 10.1080/0142159X.2019.1630730.

68. Dornan T, Boshuizen H, King N, Scherpbier A. Experience-based learning: a model linking the processes and outcomes of medical students' workplace learning. Med Educ (2007) 41(1):84-91. doi: 10.1111/j.13652929.2006.02652.x.

69. Bauer TN, Erdogan B. Organizational socialization: The effective onboarding of new employees. APA handbook of industrial and organizational psychology, Vol 3: Maintaining, expanding, and contracting the organization. APA handbooks in psychology ${ }^{\circledR}$. Washington, DC, US: American Psychological Association (2011). p. 51-64.

70. Phillips C, Esterman A, Kenny A. The theory of organisational socialisation and its potential for improving transition experiences for new graduate nurses. Nurse Educ Today (2015) 35(1):118-24. Epub 2014/08/26. doi: 10.1016/j.nedt.2014.07.011. PubMed PMID: 25149106.

71. Sandars J, Cleary TJ. Self-regulation theory: applications to medical education: AMEE Guide No. 58. Med Teach (2011) 33(11):875-86. Epub 2011/10/26. doi: 10.3109/0142159x.2011.595434. PubMed PMID: 22022899.

72. Billett S. Learning through work: workplace affordances and individual engagement. Journal of Workplace Learning (2001) 13(5):209-14. doi: 10.1108/EUM0000000005548.

73. Billett S. Toward a Workplace Pedagogy: Guidance, Participation, and Engagement. Adult Education Quarterly (2002) 53(1):27-43. doi: 10.1177/074171302237202.

74. Billett S. Learning through health care work: premises, contributions and practices. Med Educ (2016) 50(1):124-31. doi: https://doi.org/10.1111/medu.12848.

75. Varpio L, Paradis E, Uijtdehaage S, Young M. The Distinctions Between Theory, Theoretical Framework, and Conceptual Framework. Acad Med (2020) 95(7):989-94. doi: 10.1097/acm.0000000000003075. PubMed PMID: 00001888-202007000-00021.

76. Davies-Kabir M, Aitken G. Learning styles in medical education: a scoping review. MedEdPublish (2021) 10.

77. Schaap H, Baartman L, de Bruijn E. Students' Learning Processes during School-Based Learning and Workplace Learning in Vocational Education: A Review. Vocations and Learning (2012) 5(2):99-117. doi: 10.1007/s12186-011-9069-2. PubMed PMID: WOS:000305216800002.

78. Hager P, Hodkinson P. Moving beyond the metaphor of transfer of learning. British Educational Research Journal (2009) 35(4):619-38. doi: 10.1080/01411920802642371. 
79. Kilminster S, Zukas M, Quinton N, Roberts T. Preparedness is not enough: understanding transitions as critically intensive learning periods. Med Educ (2011) 45(10):1006-15. Epub 2011/09/16. doi: 10.1111/j.13652923.2011.04048.x. PubMed PMID: 21916940.

80. Chaou CH, Yu SR, Chang YC, Ma SD, Tseng HM, Hsieh MJ, et al. The evolution of medical students' preparedness for clinical practice during the transition of graduation: a longitudinal study from the undergraduate to postgraduate periods. BMC Med Educ (2021) 21(1):260. Epub 2021/05/08. doi: 10.1186/s12909-021-02679-8. PubMed PMID: 33957907; PubMed Central PMCID: PMCPMC8101179. 